when resources are tight health authorities should spend a higher proportion of their revenue on research and evaluation.

Another potential danger is researchers fighting with each other. Too often those who believe in randomised controlled trials are scornful of those interested in observational research, while biostatisticians mock economists, quantitative researchers question the value of qualitative research, and basic scientists denigrate clinical research. Professor Their called on researchers to avoid fighting each other, saying: "Nobody here has a methodology that will answer all my needs." Those who care about health must make sure that they are using the best methods to answer the tough questions they confront. And the discussions at the conference provided many examples of where researchers could get real assistance from other disciplines.

The conference heard many times about the enormous scientific excitement that is being generated by the new biology and how molecular biology is drawing together clinical researchers who previously worked on disparate physiological systems. Tom Lee, who runs the clinical effectiveness training programme at Harvard, described how studying methods for evaluating clinical practice was doing exactly the same: those evaluating treatments in gynaecology can work together with, and learn from, those evaluating gastroenterological treatments.

The central message of this conference was that health services need both research that will develop new ideas and treatments and research that will help evaluate them and ensure that those that are effective are introduced rapidly into treatment.

RICHARD SMITH Editor

$B M f$

London WC1H 9JR

\footnotetext{
1 House of Lords Select Committee on Science and Technology. Priorities in medical research. London: HMSO, 1988.

2 House of Lords Select Committee on Science and Technology. Medical research and the NHS reforms. London: HMSO, 1995.

3 Research and Development Task Force. Supporting Research and Development in the NHS. London HMSO, 1994.
}

\title{
Consensus on red cell transfusion
}

\section{Critically ill patients are often short of blood}

Perioperative blood and red cell transfusion in elective surgery varies, apparently without justification, among clinical units. ${ }^{1}$ Guidelines have not been agreed about when to give a transfusion and how much blood to give. Evidence has not been gathered to justify the heterogeneity of transfusion practice, which exposes recipients to numerous hazards, albeit a small risk per "donor exposure."2

Previous attempts have been made to establish guidelines: in 1988 the US National Institutes of Health's consensus conference on perioperative transfusion proposed that a haemoglobin concentration of $<70 \mathrm{~g} / 1$ justified transfusion. The recommendations, however, were so hedged around with the need to consider patients' clinical problems individually that the suggested haemoglobin concentration was only a small component in the decision. ${ }^{3}$ This is entirely appropriate as the haemoglobin concentration or packed cell volume alone gives insufficient information on which to base a decision to give a transfusion.

These uncertainties explain the consensus conference at the Royal College of Physicians of Edinburgh last year. Topics that were discussed included variations in transfusion practice and their clinical outcome, clinical guidelines and protocols, blood components and synthetic alternatives that carry oxygen, autologous transfusion, the need to give relevant information to patients about hazards and benefits, and, finally, means of achieving changes in clinical transfusion practice. ${ }^{4}$ The consensus statement that emerged carries clear therapeutic guidelines only a little further, and it calls for more research to help the decision on red cell or blood transfusion.

For the past 30 years transfusion specialists have sought to minimise blood transfusion, thereby avoiding avoidable hazards and using it only in patients who genuinely need it. Risks include the transmission of (especially viral) infection; immune modulation, leading to an increase in postoperative wound infections and perhaps later development of metastatic malignancy; and disasters due to clerical error, ${ }^{5}$ which autologous transfusion does not avoid. Increased awareness of these risks has led to better medical education; the adoption of maximum surgical blood ordering schedules, which establish the appropriate number of packs of blood that should be available as a precaution to replace blood loss during elective surgical procedures; and closer attention to operative haemostasis.

\section{Risk of undertransfusion}

Guidelines have been published by the British Committee for Standards in Haematology, usually in haematological journals. $^{2}$ Topics include the use of fresh frozen plasma, platelets, and transfusion schedules for infants and children. ${ }^{6}$ The need for further guidelines, however, is well recognised. These will have to be based on research, which should lead to the development of physiologically and clinically rational bases for red cell and blood transfusion-for example, after trauma and surgical blood loss. Consensus is needed not only on "triggers" prompting transfusion but also on "targets"that is, clinical and laboratory indicators that the volume of blood transfused is adequate to meet the individual patient's need for circulatory support, thereby avoiding further transfusions, with their inherent risks.

Despite the desirability of adopting ways to minimise transfusion we must not forget the risks of undertransfusion in some groups of patients who are critically ill. ${ }^{7}$ Preterm infants denied placental transfusion at birth, ${ }^{8}$ patients after cardiovascular surgery and neurosurgery, ${ }^{9-11}$ and patients dependent on a ventilator in intensive care or high dependency units fall into this category. Undertransfusion increases patients' risks of prolonged dependence on respiratory support with all its costs and complications, including infections and inadequate organ perfusion, leading to cardiac ischaemia, ${ }^{10}$ lung dysfunction, renal impairment, and multiple organ failure. ${ }^{12}$

As a guide to the adequacy of the individual patient's blood for oxygen transport and organ perfusion, which determines the outcome in critical illness, the haemoglobin concentration 
provides only half the information needed. In the critically ill the packed cell volume (which represents, like the haemoglobin concentration, merely a ratio of cells to plasma) does not predict the blood volume. The falls in plasma volume resulting from failure of the integrity of the vascular endothelium render the haemoglobin concentration a poor guide to the amount of blood in the circulation; despite haemoglobin concentrations within the normal range, blood volume may be four to six units of blood (1.5-2.5 litres) less than normal; the additional data needed are the total circulating blood volume ${ }^{12}$ and an estimate of the patient's oxygen requirements. From these the amount of donor blood transfusion required by the critically ill patient can be estimated. ${ }^{13}$

Research on this topic will help to decide whether a particular patient needs a transfusion. Such analysis can also predict from the haemoglobin concentration and circulating blood volume whether the patient's blood is already adequate for systemic oxygen transport and organ perfusion. Currently, methods of estimating blood volume are applicable only in research and in a few patients, and methods capable of repeated, widescale clinical application are needed. Such developments would greatly help to rationalise surgical resuscitation after blood loss and to monitor critically ill patients. $^{12}$

C A JWARDROP

Senior lecturer in haematology

B M HOLLAND

Consultant paediatrician

J GARETH JONES

Senior lecturer in biochemistry

Department of Haematology,

University of Wales College of Medicine, Cardiff CF4 4XN
1 Myhre BA. To treat the patient or to treat the surgeon. $3 A M A 1991$;265:97-8.

2 Jennett B, McClelland DBL, eds. Optimal use of donor blood. Edinburgh, The Scottish Office, 1995.

3 A consensus conference: perioperative red cell transfusion. $¥ A M A$ 1988;260:2700-3.

4 Royal College of Physicians of Edinburgh. Red cell transfusion. Consensus conference, 9 and 10 May 1994 proceedings. Edinburgh: RCPE, 1994.

5 Contreras M, De Silva M. Preventing incompatible transfusion. BMF 1994;308:1180-1.

6 British Committee for Standards in Haematology Task Force (D Voak, chairman). Guidelines for administration of blood products: transfusion of infants and neonates. Transfusion Med 1994;4:63-9.

7 Lenfant CA. Transfusion practice should be audited for both under-transfusion and overtransfusion. Transfusion 1992;32:873-4.

8 Kinmond S, Aitchison TC, Holland BM, Jones JG, Turner TL. Umbilical cord clamping and preterm infants: a randomised trial. BMF 1993;306:172-5.
9 Dunn GS, de Souza PR, Wardrop CAJ, Stuart AG. Covert anaemia and hypovolaemia after cardiopulmonary surgery. The need for transfusion targets. Eur Heart $f$ 1995;16:111.

10 Nelson A, Fleischer LA, Rosenbaum SH. Relationship between postoperative anaemia and cardiac morbidity in high-risk vascular patients in the intensive care unit. Crit Care Med 1993;21: 860-6.

11 Gerber CJ, de Souza PR, Goringe A, Wardrop CAJ, Simpson BA. Optimising oxygen delivery in neurosurgical patients-assessment of transfusion requirements. I Neurol Neurosurg Psychiatry (in press).

12 Wardrop CAJ, Holland BM, Jacobs S, Jones JG. Optimization of the blood for oxygen transport and tissue perfusion in critical care. Postgrad Med 7 1992;68(suppl 2):S2-6.

13 Jones JG, Holland BM, Hudson IRB, Wardtop CAJ. Total circulating red cells versus haematocrit as the primary descriptor of oxygen transport by the blood. Br $f$ Haematol 1990;76: 288-94.

\title{
Friday the 13th and obsessive compulsive disorder
}

\author{
Better understanding has brought some success in treatment
}

Most readers of this journal are probably not superstitious. They are unlikely to change their behaviour this Friday the 13th despite a study showing significantly more road traffic accidents on Friday the 13th than Friday the 6th. ${ }^{1}$ They might, however, "touch wood" or choose a lucky number in the national lottery. People who are superstitious take it further. They see a causal relation between their own thoughts or actions and events in the world. Superstitions flourish whenever people cannot tolerate uncertainty or believe that they have no control over events; they lead us to believe that we can influence outcomes. Superstitiousness correlates significantly with the obsessional thoughts and compulsive checking experienced by people with obsessive compulsive disorder. ${ }^{2}$

Obsessive compulsive disorder consists of obsessions or compulsions or, most commonly, the two combined. Obsessions are recurrent intrusive thoughts, images, or urges that cause considerable anxiety or disgust. Typical obsessions concern contamination, misfortune, violence, blasphemy, and sex. Compulsions are thoughts or actions that a person feels driven to repeat. They include ritualistic cleaning, checking, counting or touching of objects, hoarding, and superstitious behaviour. According to one cognitive model, people with obsessive compulsive disorder experience fusion of their thoughts and actions. ${ }^{3}$ Having a bad thought (about, for example, abusing a child) becomes morally equivalent to doing the act itself, while failing to prevent a bad event becomes equivalent to being responsible for the harm inflicted.

A recent epidemiological survey in the United States found that obsessive compulsive disorder was the fourth most common psychiatric disorder in the community but that many sufferers did not seek help or took up to 10 years before consulting a health professional. ${ }^{4}$ Sufferers typically try to suppress intrusive thoughts. They may also try to neutralise them by using mental rituals such as counting to 10 or reciting simple rhymes to themselves. These attempts to suppress or neutralise intrusive thoughts can, however, make matters worse, since they tend to reinforce the obsessive compulsive behaviour patterns.

Our understanding of the biological correlates of obsessive compulsive disorder has progressed, allowing us to integrate biological and psychological models. ${ }^{5}$ Of particular interest have been reports suggesting that people with the disorder have smaller caudate nuclei than healthy controls, leading to inadequate filtering of outputs from the orbitofrontal region of the brain. ${ }^{67}$

The main options for management are behaviour therapy, cognitive therapy, and treatment with drugs. In behaviour therapy the patients are helped to face the situations that they have been avoiding and to resist ritualistic responses to their compulsions. About a quarter of patients, however, either decline such treatment or drop out once it has started. Of those who participate, about three quarters respond well. ${ }^{8}$ Some patients may benefit from establishing their own programme of behaviour therapy with the help of lay volunteers. Cognitive therapy entails teaching patients to recognise obsessions simply as thoughts. Patients are encouraged to make realistic estimates of the likelihood of a bad event actually happening and of the degree of their responsibility for it if it did happen. A recent trial suggests that cognitive and behavioural therapy are equally effective," and there is growing interest in integrating the two. 